\title{
ENTREVISTA A DOMÉNICO CHIAPPE
}

Nohelia Meza*

Bryan Barrachina*

RESUMO: En esta entrevista, Doménico Chiappe nos habla de la estructura de sus obras, de la experiencia de narrar hilando diferentes lenguajes. El autor hace énfasis en la fusión de diversas artes en las obras multimedia y subraya la necesaria convergencia de distintos artistas para su elaboración. Chiappe profundiza en los términos: brevedad, circularidad, fragmentación, hiperfonía y retórica multimedia, al mismo tiempo que nos explica cómo estos afectan tanto el proceso creativo como las diferentes formas de lectura que de él se originan.

TD: ¿Podrías hablarnos sobre las imposiciones del medio (brevedad, circularidad, fragmentación) las cuales mencionas en tu artículo "Enveloping Literature and Other Challenges to the Multimedia Author" (2012)?; ¿y cómo esto se refleja en la creación de tu nueva obra Hotel Minotauro (2013) y en Tierra de Extracción (2007)?

D. Chiappe: Me gusta pensar en las obras multimedia como un gran círculo de mercurio, aunque la imagen, que alguna vez fue casera, ya sea obsoleta. En nuestros hogares había mercurio en el termómetro y, cuando se rompía, entre los añicos, había una pelotita plateada, de apariencia pura y perfecta, con la que jugabas con fascinación: si la aplastabas, se formaban más bolitas, igual de perfectas en su redondez. Si las juntabas, se acoplaban sin perder esa forma, sin hacer ningún esfuerzo manual. Las lexías de las obras literarias multimedia pueden -a mi entender, deben- ser así, como esos fragmentos de mercurio. Funcionar con perfección narrativa en un diminuto eslabón en el que su circularidad esté estructurada en una historia con principio y final. Que si se une a otro eslabón,

\footnotetext{
* Grupo de Investigación Hermeneia Estudios Literarios y Tecnologías Digitales y doctoranda en el departamento de Traducción y Ciencias del Lenguaje. Universidad Pompeu Fabra, Barcelona.

** Grupo de Investigación Hermeneia Estudios Literarios y Tecnologías Digitales, Universitat de Barcelona.
} 
componen una historia mayor, pero igual de completa. A medida que se fusionan las piezas, crece y hace más compleja la obra, pero mantiene su circularidad de mercurio. Para tener fuerza y coherencia combinatoria, las lexías -o nodos o eslabones o esporas- pueden -deben- ser breves, sin renunciar a transmitir una visión particular, y no solo pueden sostenerse, en esa transmisión del mensaje, en el texto, sino en los demás lenguajes que lo digital permite e invita a sumar.

Hotel Minotauro es una obra mucho más breve que Tierra de extracción, pero también más exacta, con una poética precisa, y funciona con este tipo de eslabones para contar varias tramas: 1) el minotauro envejecido que busca a una mujer, apoyado en una visión subjetiva del monstruo que avanza por el pasillo de un hotel, en el que aparecen textos propios del narrador omnisciente; 2) la de la mujer buscada, una historia real apoyada en fotografías bajadas de internet e intervenidas, en la que la historia prescinde del texto; 3) la del espectador: cada uno en un eslabón/ pantalla, son varios, desde dirigentes (políticos, burócratas de organismos multilaterales, empresarios) hasta sus víctimas (en las canciones y sus letras) y voyeurs de foros y chats, en una retórica textual inspirada en los grabados de Goya, sobre todo en Los desastres de la guerra, y con un lenguaje visual de este tiempo, de sutiles arquitecturas 3D y recreaciones de capturas de pantalla. Aquí interviene la idea y el arte de cada uno de quienes participaron: David Losada, Jesús Jiménez, Fidel Cordero...Cada eslabón cuenta una historia mínima, con un juego de sugerencias y claroscuros, pero se enhebran para arrojar la solución a la búsqueda del minotauro. Circularidad.

TD: Al experimentar tu obra, vino a nuestra mente el Hypertext Hotel (19931996) de Robert Coover; ¿encuentras ecos entre la propuesta de Coover y Hotel Minotauro (2013)? Quizás en el sentido no-lineal, no secuencial de las historias, ¿en la parte "detective-puzle" o "recopilación de piezas" que lo tiñe?; ¿lo llegaste a asociar o a pensar?

D. Chiappe: Las propuestas literarias que se han trasladado a lo digital, con todas sus particularidades y crecimiento a partir de las exigencias del medio, replican aquello que la literatura ha explorado durante siglos, y que se demuestra eficaz para 
contar historias y transmitir temas. Hotel Minotauro bebe de los maestros en el manejo de la tensión, la estrategia temporal, la precisión de la prosa, la dosificación de información para mantener el misterio. Los relatos negros siempre han sido construcciones de puzles. Poe, por ejemplo. Entonces, partiendo de esta tradición, que sería inútil e ineficiente desconocer, se juega con las palabras y con la estructura nuclear que se acomoda en la superestructura de la obra multimedia. Lo novedoso en la manera electrónica de narrar no es el conjunto de la técnica literaria, sino la forma de hacerlo con lenguajes que hasta la aparición del espacio electrónico vivían en formatos separados, y ampliar la interacción y participación del lector/ usuario/ navegante/ lectoautor o como quiera llamársele. Debo admitir que esta obra de Coover no la conozco (la sumaré a los "libros" que aguardan lectura) como tampoco he sido un gran jugador de videojuegos de detectives que transcurren en hoteles (me viene a la cabeza Hotel Dusk) pero la no-linealidad se ha ensayado también desde mucho antes de la aparición de la tecnología digital y, siendo el tiempo un crítico implacable, suelo regirme e inspirarme en aquellas pocas obras que han sobrevivido a su paso.

\section{TD: ¿Podrías hablarnos sobre los términos hiperfonía y retórica multimedia?; ¿considerarías ya estos términos como una particularidad de tu obra?}

D. Chiappe: La hiperfonía es un término que ensamblé a mediados de 2000 para hablar de esa polifonía creativa, existente en la metaobra, en el proceso creativo. Ahora no sé si es afortunada, el prefijo "hiper"... Quería referirme al conjunto de conciencias/ visiones/ mentes que intervienen en una obra que, a su vez, trata un universo desde las múltiples conciencias de sus personajes o narradores. La polifonía sobre la mesa de los creadores envolviendo la polifonía de la diégesis. Es una particularidad que me gusta resaltar en mis obras, esa participación, el aporte de otros creadores. No encuentro una forma mejor de labrar esa retórica multimedia, aunque sea más fatigoso trabajar en colaboración, y hay más ideas abortadas que producciones que mostrar. Sin embargo, creo que, si se supera esta complejidad, la obra sale ganando.

\section{TD: Hablemos de música, elemento básico de tus creaciones; ¿cómo haces la}


selección de la música que eliges para cada obra?; ¿está relacionada con la parte hiperfónica que quieres resaltar?; es decir, ¿una forma de representación del sonido que lleva de la mano a la narrativa y a la vida de cada personaje?

D. Chiappe: Cierto, ustedes tienen razón en que es un elemento básico de mis creaciones, y punto de partida, quizás sentimental, de las sensaciones que quiero transmitir. Creo que las obras multimedia irán hacia un espacio envolvente, una evolución de la pantalla hacia la inmaterialidad, que rodeará al espectador/ lector aun a su pesar, en el espacio público. Y en esta relación obra-autor-público la música y el arte sonoro, así como quizás los olores, serán cruciales.

Desde Tierra de extracción, que tiene catorce canciones fragmentadas en cuarentitantas piezas, cada composición pertenece a un personaje. Es su voz, aquella que el narrador es incapaz de comprender y transmitir, sea que tenga letra o que sea instrumental. La música la compongo yo y suelo trabajar con músicos profesionales con quienes comparta afinidades. En el caso de Hotel Minotauro, hay tres piezas. La que resuena en el pasillo es "La voz del monstruo", instrumental, un solo de guitarra que interpreto sobre una serie de sonidos ambientales. Es una forma más primitiva y salvaje de "hablar", de exteriorizar el sentimiento de quien tiene cabeza de toro. Las otras dos son "Títeres" y "La fuerza del rencor", que son las voces de quien padece la acción de otro más poderoso, de un sistema. De forma directa, es la voz del personaje que aparece en la trama, pero también podría ser la voz de un país, de una sociedad. Una es la voz femenina, otra masculina. Una habla con sumisión y tristeza, la otra con rabia y tensión. Me gusta jugar con las contraposiciones constantes también en la literatura que escribo para el papel (caso, por ejemplo, de Tiempo de encierro, cuyos engranajes se sostienen en esos choques y paradojas).

Más que en cuanto a hiperfonía, la música es parte esencial de lo polifónico, según la definición de Bajtín. En Tierra de extracción, por ejemplo, donde los personajes transitan su "arco de transformación", la/s canción/es que les acompaña/n también varían, y, divididas en partes, cada parte tiene arreglos distintos. En Hotel Minotauro, 
al contrario, más relato que novela, los personajes no cambian. En este relato he trabajado más en el instante, en el conjunto de momentos breves.

TD: En lo que concierne a la creación de esta nueva obra de literatura digital, en la que suponemos colaboraste con otros artistas como en Tierra de Extracción (2007), ¿cambiaste algo en la forma de trabajar en equipo después de haber tenido la experiencia anterior?

D. Chiappe: En Tierra de extracción trabajé en solitario durante varios años, con la composición musical, el texto y sus reescrituras, el guión, la producción general, la búsqueda de imágenes y colaboradores. Luego intervinieron dos equipos de diseño y programación, uno para la primera versión, presentada en 2000 , y otro en la segunda, presentada en 2006, con lo que se cerraban 10 años de trabajo, y aprendizaje de lo que se podía y lo que quería hacer. Ensayo y error, tanteos, test, largos periodos improductivos, otros intensos.

Sin embargo, en Hotel Minotauro el conjunto nació al mismo tiempo. Los contenidos los escribí sobre el guion. Había esa superestructura del multimedia rigiendo desde el principio la forma de narrar. Sabía con más exactitud que en Tierra de extracción qué quería contar, cómo quería enhebrar las historias y también los lenguajes de cada una. La realización también fluyó mejor gracias a la colaboración con Maloka Media, la productora que se hizo cargo de su puesta en escena. Varió la visión. Pero también preponderó la idea de no repetir un guion o un ensamblaje como el de Tierra de extracción. La reiteración hubiera sido fácil, y el reto como autor hubiera sido nulo. Así que, si en Tierra de extracción el usuario/ lector se encontraba fuera de la obra, en Hotel Minotauro había que variar esa perspectiva y colocarlo dentro. Si en una había botones, aquí debía ahondarse en la intuición y sustituirlos por atrezzo. Si en la anterior había un mapa y mil brújulas, aquí el propósito era mantener una desorientación.

TD: ¿Cómo consideras que el formato “videojuego" en primera persona que parece adoptar tu nueva obra Hotel Minotauro (2013) tendrá influencia en la interpretación que el lector hará de la obra en su totalidad?

Texto Digital, Florianópolis, Santa Catarina, Brasil, v. 12, n. 1, p. 134-143, jan./jun. 2016. ISSNe: 1807-9288. 
D. Chiappe: Es parte del ensayo. Asumo riesgos. Al jugador nativo de videojuegos quizás le parezca natural o una torpeza. Al acostumbrado a la linealidad y lectura cenital, quizás le asombre o le espante. En Hotel Minotauro, aunque buscamos intencionalmente esa estética de videojuego y esa vista de apariencia subjetiva, también quisimos que hubiera lectura, y no solo la lectura metafórica. Quisimos que el texto tuviera un rol protagonista y encontrara equilibrio con lo demás: fotografía, animación, música, diseño. Hay suficiente espacio, entre los contenidos y sus vertebraciones, para que cada lector tenga una interpretación propia. Nada concluye, y cuando crees encontrar la salida, vuelves al inicio, porque, de alguna forma, el alzhéimer que afecta al minotauro también influye en quien le acompaña.

TD: ¿Si en Tierra de extracción (2007) recurrías a la palabra para llevar mayormente el hilo de la historia, se repite el caso en Hotel Minotauro (2013) o has, tal vez, añadido algún elemento nuevo?

D. Chiappe: Hay una historia contada con palabras. Pero en ambas hay más historias que se cuentan con otra retórica. En Tierra de extracción estas historias pueden ser una centena apoyadas en la fotografía como medio, algunas como un golpe visual. En Hotel Minotauro el diseño favorece que haya menos jerarquía que en Tierra de extracción, más apegada al papel, a la construcción usual de las superficies literarias. Como decía antes, creo que lo experimentable, lo que puede hallar algo innovador, es cómo los elementos comulgan y conviven en un espacio único. Cómo haces danzar cada componente en el espacio intangible y atemporal que existe al otro lado de la pantalla.

TD: Has dicho que Hotel Minotauro (2013) está basado en la investigación de un crimen; por tanto, si consideramos que para resolver el crimen, el hotel se convierte en un pasaje digitalmente laberíntico entonces podríamos pensar que el lector que experimenta tu texto tiene una doble labor de investigación: ¿la reconstrucción de la historia a través de la reconstrucción del texto mismo? 
D. Chiappe: Es muy buena esa afirmación: "la reconstrucción de la historia a través de la reconstrucción del texto mismo". Es una interpretación, una de ustedes como lectores que a mí no se me había pasado por la cabeza. La historia de Hotel Minotauro encierra varios tropos, juegos de metonimia y de metáforas. El laberinto como hotel como internet. El acéfalo como monstruo como usuario que renuncia a su cabeza, como aquellos que en la retórica pornográfica van cámara en mano (Narciso podría serlo del selfie o de los reflectogramas). El protagonista que en ese laberinto/ hotel/ red pierde la memoria, cuando los ordenadores e internet son máquinas de memoria y, al traspasar las puertas, se convierte, por momentos, en una especie de Funes, que recuerda y revive, pero que, al actuar y avanzar vuelve a perderse en la sobreinformación y el olvido. Un hotel, sitio de descanso, donde no se descansa... El lector, como ustedes afirman, está obligado a reconstruir el texto, pero también a vivir la experiencia.

TD: Tomando esto en cuenta, ¿consideraste en algún momento la representación de un hotel sin salida o de difícil salida? (siguiendo la idea de laberinto) ¿o tu idea estaba más enfocada a crear un hilo digital que mostrara la salida al lector a partir del ícono "Exit"?

D. Chiappe: Otra paradoja. Exit : salir solo te retorna al principio. A la voz del monstruo, a su lamento rabioso y cadencioso, a su búsqueda, porque al final encuentra el por qué no encuentra lo que busca; una solución frustrante que olvida de inmediato, al traspasar esa puerta de servicio, de salida de emergencia, que solo es un engaño más. De esa red, de esa memoria ajena que no logra consolidar su información.

TD: ¿Por qué has decidido partir de la mitología griega para la creación de Hotel Minotauro (2013)?; ¿has considerado los trabajos con alusión al Minotauro de Cortázar, Dante, Picasso, o Borges, -entre otros- para tu creación (una nueva aproximación al tema en las esferas de la literatura digital)? Y, de esta manera, ¿unirlo con los tintes socio-políticos que evocan los textos? 
D. Chiappe: Sí, exactamente, me interesa esa continuidad del tema, de trabajos y visiones. No creo que lo original de la literatura digital sea hablar de lo contemporáneo y tecnológico. La literatura "analógica" (como la llama Laura Borràs) ha logrado obras maestras sobre estos temas. Lo innovador, como digo, es la forma. La forma de la narración. Y en ese sentido es un reto construir una narración que, en la tradición textual, puede ser sucesora de estos ejemplos que mencionan. O intentarlo. El mito griego y su complejidad. El minotauro en una esfera actual que probablemente no dista demasiado a la que había en sus años primeros. Como símbolo también de la confrontación a una realidad tan compleja que a veces no puede comprenderse por existir datos ocultos, y donde los ciudadanos solo pueden embestir, pues han sido desarmados de razón y despojados de influencia, como vemos hoy. $\mathrm{Y}$, al mismo tiempo, la víctima, ese personaje embrutecido y desmemoriado, es también victimario, reproduce lo patriarcal y machista. La idea surge a partir de una invitación de Fernando Marías, para hablar de un monstruo y su soledad. De todos, el minotauro era el personaje idóneo para lo que quería contar y cómo.

TD: En términos de lectura, ¿consideras que el lector acostumbrado a la literatura sobre papel tendrá menos capacidades a la hora de entender la obra y su contenido que un nativo digital?

D. Chiappe: Lo veo desde otro punto de vista: es muy probable que estas obras que creamos los que pertenecemos a generaciones híbridas, sean ingenuas para un nativo digital. Creo que las capacidades de autores como yo entablan un diálogo con una generación similar, pero que las que vienen criadas con el uso de las tecnologías y las redes sociales tienen una retórica y una relación con lo digital muy distinto a lo que yo puedo procesar. Los nativos digitales tendrán sus autores y sus ídolos, y sus retóricas y sus modos, tan válidos y artísticos como los que pretendemos labrar nosotros. Quizás nosotros y nuestras obras seamos pronto solo una referencia, un antecedente, parte de una tradición.

TD: Al decir que el libro virtual está en el tiempo de la incunabula (the time of incunabula; a time of formation); desde tu experiencia como autor multimedia 
y pre-multimedia, ¿cómo percibes tus publicaciones futuras de literatura digital?

D. Chiappe: Tengo, desde hace ya algunos años, una idea que quisiera desarrollar, que va en ese intento de literatura envolvente, de obra digital líquida que, sin embargo, en mi concepción, se sostenga solo de letras y palabras, actuando no solo semánticamente. Esta obra está proyectada para intervenir el espacio público, rodear al espectador, formar una cúpula, una cartografía, un mapa astral. Es un proyecto, bocetado en el papel que todo lo sostiene, que no he podido llevar a la práctica por carecer de ese tanque hiperfónico que siempre busco como aliado. De momento. Cuando lo pensé, cuando comencé a elaborar los contenidos, no existían las tablet. Quizás dentro de unos años se materialice, o no.

\section{TD: Gracias por compartir tu tiempo y conocimiento con nosotros, Doménico.}

D. Chiappe: Gracias a ustedes.

\section{Obras citadas}

CHIAPPE, Doménico, et al. Tierra de extracción. 1996-2007. Último acceso 24 de noviembre de 2014. URL: <http://www.domenicochiappe.com/pg_d_12a.html>.

CHIAPPE, Doménico, etal. Hotel Minotauro. 2013. Último acceso 24 de noviembre de 2014. URL: <http://www.domenicochiappe.com/pg_d_11a.html>.

COOVER, Robert. The Hypertext Hotel. 1993-1996.

CHIAPPE, Doménico. "Enveloping Literature and Other Challenges to the Multimedia Author." Hybrid Storyspaces: Redefining the Critical Enterprise en Twenty-First Century Hispanic Literature. Ed. Christine Hensler and Deborah A. Castillo. Hispanic 
Issues On Line 9 (Spring 2012): 40-49. Último acceso 24 de noviembre de 2014. URL: <http://hispanicissues.umn.edu/assets/doc/04_CHIAPPE.pdf>.

\section{INTERVIEW WITH DOMÉNICO CHIAPPE}

ABSTRACT: Domenico Chiappe writer, journalist, teacher, and author of Tierra de Extracción (2007) gives us an insightful look as to what lies beneath, through and within his latest digital novel Hotel Minotauro. Once again, Chiappe dives deep into the complexities of composing a hypermedia novel with a strong literary backbone and delights us with the real life stories behind them. 